\title{
A noção de comunidade científica de Francis Bacon: Uma leitura da Casa de Salomão na Nova Atlântida
}

\section{Francis Bacon's notion on scientific community: A read of the Salomon's House in the New Atlantis}

\author{
Kailani Amim Postilhoni Ferreira \\ Graduando em Filosofia, Universidade Estadual Paulista - UNESP, Campus de Marília, SP, Brasil.
}

Resumo: Pretendemos, neste artigo, apresentar quais elementos na filosofia de Francis Bacon contribuem para a formação de uma noção de comunidade científica, em voga na ciência moderna. A obra Nova Atlântida é o escopo do como ele idealizava a comunidade científica, ilustrando-a fictícia instituição chamada Casa de Salomão, que fica na utópica ilha de Bensalém. Estabelecendo relações com o projeto científico criado por Bacon, mostraremos como a Casa de Salomão corporifica a ideia do autor em criar uma comunidade científica.

Palavras-chave: Francis Bacon; Nova Atlântida; Casa de Salomão; Comunidade Científica

\begin{abstract}
Our goal on this article is to present which are the elements in Francis Bacon's philosophy auxiliary for the formation of a scientific community notion, present in the modern science. The work New Atlantis is the scope of how he idealized a scientific community, illustrating it in the fictional institute called Salomon's House, situated in the utopic island Bensalem. Establishing relation between the scientific project created for Bacon, we show how the Salomon's House embodies the Bacon's idea in create a scientific community.
\end{abstract}

Keywords: Francis Bacon; New Atlantis; Salomon's House; Scientific Community 
Hoje em dia vemos os cientistas pesquisarem e exporem seus resultados de forma a serem confirmados por seus semelhantes ou refutados pelas pesquisas destes. Conhecemos isso como comunidade científica, e Francis Bacon (1561 - 1626) é um filósofo cujo pensamento impactou a ciência moderna, junto de outros intelectuais de seu tempo como Galileu Galilei e René Descartes. Ao lado deles, foi um dos mentores da ciência moderna; talvez o de maior peso para ela (ROSSI, 1996).

Em seu sistema, Bacon elucida o teor cooperativo de sua ciência pautada em um método indutivo e experimental. Planejava que os filósofos naturais (algo semelhante, porém não igual, aos que são hoje chamados cientistas, uma vez que os primeiros estudam as causas dos fenômenos naturais enquanto que os segundos apenas os descrevem) comunicassem suas descobertas, como também prescrevessem seus resultados e que, com isso, suas hipóteses pudessem ser corroboradas ou refutadas por outrem. Tal ambição de instituir uma comunidade científica foi ilustrada pelo filósofo inglês na obra Nova Atlântida ${ }^{1}$, na qual encontramos a instituição científica chamada de Casa de Salomão (ou Colégio da Obra dos Seis Dias) sediada na ilha de Bensalém. De caráter utópico, a obra faz parte da literatura política renascentista, que segundo Steiris "expressava a terminante demanda por uma reforma geral ética e política, de modo a promover o bem-estar da sociedade e felicidade humanas" (2013, p. 58, tradução nossa), como também o caso da Utopia de Thomas More e A Cidade do Sol de Tommaso Campanella. No caso de Bacon, sua sociedade ideal seria governada não apenas por um bom governo, mas, também, por um governo que incentiva a atividade científica e usa seus resultados para o bem comum, objetivos promovidos pela Casa de Salomão.

Embora não planejada exatamente como atualmente a concebemos, a comunidade científica presente na utopia baconiana influenciou a nossa atual concepção, algo refletido historicamente com o surgimento da The Royal Society. Joseph Glanvill², citado por Sargent (1996), menciona a Casa de Salomão como um "projeto profético da Royal Society" (p. 166, tradução nossa). Desde sua fundação em 1660, a instituição inglesa promoveu, de certa maneira, a realização do sonho baconiano em comportar os filósofos naturais a uma associação que permitisse troca de experiências e aplicação de conhecimentos para o bem comum. Embora na mesma época houvessem outras academias científicas surgindo pela Europa, como a Académie des Sciences na França, a Royal Society, no entanto, é aquela cuja presença na história da ciência foi mais notória, e indiretamente Francis Bacon participou desse marco como um inspirador dessa sociedade científica da qual ele é patrono ${ }^{3}$.

Para que fique claro como a Casa de Salomão é um elemento importante na ciência segundo Bacon, especificamente na noção que ele veio a construir de comunidade científica, primeiro elucidaremos o caráter cooperativo que o método baconiano permite, fazendo breves recortes do Novum Organum (doravante NO) ${ }^{4}$ e o Advancement of Learning (O Progresso do Conhecimento), apresentando os elementos necessários do sistema baconiano sem expor suas minúcias. Feito isso, explicaremos como Bacon

\footnotetext{
${ }^{1}$ A Nova Atlântida é um livro póstumo de Bacon. Escrita em 1626, foi publicada inacabada um ano após sua morte, redigida originalmente em inglês. A pedidos do próprio Barão de Verulâmio, William Rawley, seu assistente, ela foi traduzida para o latim e publicada juntamente do Sylva Sylvarum.

${ }^{2}$ Joseph Glanvill (1636 - 1680) foi um teólogo e filósofo inglês, e também, um dos primeiros membros da The Royal Society.

${ }^{3}$ Historicamente, Francis Bacon é considerado uma figura patronal da Royal Society juntamente do rei Carlos II da Inglaterra (1630 - 1685), este responsável por sua fundação.

${ }^{4}$ A edição utilizada é uma tradução para o português feita por José Aluysio Reis de Andrade (1979). As citações diretas e indiretas dela não serão referidas pelo padrão autor, ano de publicação e página, e sim, com o título da obra abreviado, o número do livro (I ou II) e o número do aforisma assim como os demais artigos acadêmicos voltados à filosofia baconiana.
} 
imaginava sua fictícia instituição científica da Nova Atlântida, relacionando-a como uma ambição que reverbera seu próprio pensamento.

\section{I}

A ciência concebida por Francis Bacon reside, estruturalmente, em seu método. Com ele, pretendia alavancar sua Magna Instauratio (Grande Instauração), que serve para revisar a ciência que havia até sua época. Vale ressaltar que as críticas que o filósofo fazia ao conhecimento "científico" (no âmbito da filosofia natural na época) dirigia-se à filosofia escolástica fortemente aristotélica, dogmática e focada no respeito às autoridades intelectuais. Os escritos de Aristóteles, em grande parte resgatados do mundo árabe (sobretudo pelo contato com os comentários de Averróis ${ }^{5}$ ) possuíam uma "reverência apropriada de um livro sagrado" (KENNY, 2008, p. 167, tradução nossa) que permanecia veemente nas universidades tanto na Renascença quanto na Modernidade. Tratando-se de filosofia natural, os procedimentos heurísticos e justificativos eram calcados na lógica silogística aristotélica, exposta principalmente nos Segundos Analíticos. A principal crítica a esse grupo predominante nas universidades era o empecilho que essa reverência demasiada aos antigos (principalmente Aristóteles) implicava para a ciência:

\footnotetext{
“Vão seria esperar-se grande aumento nas ciências pela superposição ou pelo enxerto do novo sobre o velho. É preciso que se faça uma restauração da empresa a partir do âmago de suas fundações, se não se quiser girar perpetuamente em círculos, com magro e quase desprezível progresso" (NO, I. XXXI)
}

Ele propõe, então, não uma ruptura total com o conhecimento legado pelos antigos, reconhecendo o valor destes autores quando alega que "a antiguidade merece que se lhe preste a reverencia de apoiar-se nela e dali ver qual é o melhor caminho; mas uma vez descoberto este, há que se avançar. E, na verdade, antiquitas saeculi juventus mundi [A antiguidade dos séculos é a juventude do mundo]" (BACON, 2007, p. 57, colchetes do tradutor). Bacon, ao invés disso, faz uma suprassunção de suas contribuições: aproveita o que for útil, mas descartando aquilo que não prestar ao progresso da filosofia natural. O problema maior é, que, "o fim e a meta da ciência foram mal postos pelos homens" (NO, I. LXXXII), e isso viria de um problema axial que é o auxílio inadequado da mente humana pelo método em voga, causa esta das deficiências humanas na aquisição de conhecimento. Ao seu ver, o silogismo aristotélico seria o cerne das mazelas da filosofia natural, uma vez que este era usado como instrumento de demonstração, e segundo Bacon, Aristóteles "corrompeu com sua dialética a filosofia natural" (NO, I. LXIII) tendo-se em vista que ela "envolve nosso assentimento, não as coisas" (NO, I. XIII). A lógica aristotélica servia como instrumento de demonstração, baseada na autoevidência, o que tornava-a ao entender do filósofo inglês uma perniciosa ferramenta para o conhecimento.

De certo modo, o método que Bacon propõe também é demonstrativo, mas ao mesmo tempo é fortemente indutivo, escapando do apriorismo intrínseco ao silogismo aristotélico. Seu ataque ao aristotelismo reside no fato dele tomar conclusões precipitadas fundadas em poucos casos da experiência, salvaguardando as afirmações falsas ao invés de corrigi-las (NO, I. XXV) desde que sua estrutura lógica fosse válida, o que leva Bacon a cunhar essa filosofia como uma antecipação da natureza, também taxando o método aristotélico como uma indução vulgar. Propondo-se a superar essa

\footnotetext{
${ }^{5}$ Averróis, nome latino de Ibn Rushd (1126 - 1198), foi um filósofo andaluz de tradição islâmica. Sua filosofia foi fortemente influenciada por Aristóteles, filósofo qual também escreveu comentários acerca das obras, bem recebidos tanto por seus conterrâneos quanto mais tarde foram pelos filósofos europeus cristãos, por estes passando a ser conhecido pela alcunha de "o Comentador".
} 
indução aristotélica "vulgar", ele apresenta sua indução como indução verdadeira, que se baseia em uma gama de casos experienciados vasta, de modo a superar as carências existentes no intelecto e nos sentidos humanos provocadas pelos ídolos ${ }^{6}$.

Pelo seu método, o filósofo exalta a razão humana (quando bem dirigida a evitar os ídolos) e seu potencial em intervir sobre a natureza uma vez conhecendo suas leis e a elas submete-se, já que o conhecimento e o poder humanos são coincidentes (NO, I. III; II. IV). É certo, com isso, dizer que o conhecimento apropriado sobre a natureza - ou melhor, de seus princípios, suas leis - e a possibilidade de intervir sobre ela são coisas diretamente proporcionais entre si. O procedimento metodológico de Bacon, em poucas palavras, pode ser descrito do seguinte modo:

“O conhecimento parte da experiência sensível, repousa sobre a história natural que apresenta dados sensíveis em uma distribuição ordenada, ergue-se dos axiomas menores ou proposições aos mais gerais, tenta procurar as mais fundamentais leis da natureza (o conhecimento das formas) e, a partir daí, por dedução prática, deriva novos experimentos e obras." (MALHERBE, 1996, p. 76, tradução nossa)

Como objeto, Bacon elege as formas como escopo investigativo no primeiro aforisma do livro II do Novum Organum. A forma, em sua filosofia da natureza, é um conceito de grande peso e complexidade. Suas bases encontram-se: (1) Na sua origem terminologicamente platônica, uma vez que assim como Platão, Bacon também reconhece nas formas o objeto do conhecimento por excelência, apontando, entretanto, que o pensamento platônico "perdeu o fruto genuíno de sua teoria ao considerá-las algo totalmente abstraído da matéria" (2007, pp. 147-148); e (2) na recepção às quatro causas da metafísica aristotélica, adotando as causas material, formal, eficiente e final em seu discurso ainda que sua concordância com Aristóteles seja apenas vocabular. Das quatro, ele considera somente a causa formal como prestativa ao conhecimento científico, uma vez que não há teleologia na natureza (existindo somente nas questões humanas) e as causas material e eficiente são infrutíferas para a ciência por serem variáveis (NO, II. II).

A forma é bem definida como lei, essência e estrutura das coisas, mas sua definição gera polêmica até mesmo entre os comentadores de Bacon. Sabe-se, decerto, que o filósofo inglês acreditava que por ela a qualidade dos corpos era assegurada. Coisas como cor, peso, maleabilidade, entre outras, são formas segundo a concepção baconiana do termo. Corpos que apresentem uma mesma propriedade possuem uma forma comum; sendo assim, por exemplo, a forma da brancura é o que torna as nuvens, a esclerótica do olho humano e neve brancas. Cabe então à ciência descobrir as formas dos corpos naturais, e pela técnica, a capacidade de alterar ou adicionar formas de um corpo em outros corpos, já que "engendrar e introduzir nova natureza ou novas naturezas em um corpo dado" (NO, II. I). Recapitulando, é o propósito da ciência a descoberta das formas, uma vez que "quem conhece as formas abarca a unidade de uma natureza (a brancura, por exemplo) nas mais variadas matérias (neve, nuvem, ovo, etc) e pode produzi-la em qualquer matéria" (OLIVA, 2003, p. 40).

A ciência deve, para o Barão de Verulâmio, descobrir as formas para poder adicionar ou alterá-las arbitrariamente nas coisas como for conveniente para os fins humanos. A famosa frase do autor de que "conhecimento é poder" encaixa-se devidamente nesse

\footnotetext{
${ }^{6}$ Os ídolos são descritos por Bacon (NO, I. XXXVIII) como "noções falsas que ora ocupam o intelecto humano". Quatro são os tipos de ídolos, sendo eles apresentados respectivamente na ordem: Ídolos da tribo, ídolos da caverna, ídolos do foro e ídolos do teatro.

${ }^{7}$ No Advancement of Learning (2007), Bacon deixa claro a apropriação que ele faz de termos da escolástica, no entanto, fazendo convenientes alterações semânticas neles. Oliva (2003) comenta a respeito que o filósofo optou "por manter os termos antigos dando-lhes contudo novos significados." (p. 36), e no tocante à forma, chama a atenção para os esforços do filósofo em suas obras de "impedir uma leitura platônica, aristotélica ou escolástica do termo forma, sem contudo abdicar dele".
} 
contexto: ao usar o conhecimento das causas formais para intervir sobre elas, o gênero humano reafirma seu domínio sobre a natureza de modo que pela ciência e a técnica seja possível a "ampliação do seu poder sobre a natureza" (NO, II. LII). Modificando os corpos físicos, uma vez que os conheça em essência, a ciência baconiana possui um ressaltante rigor utilitário, havendo pela técnica uma possibilidade de ação humana, dirigida para melhorar a qualidade da vida humana e o bem da espécie de modo geral, o que dá ao projeto científico baconiano não apenas um rigor utilitário, como também um rigor normativo.

O embasamento deste rigor normativo advém da cosmovisão judaico-cristã professada por Bacon, pois ela adverte o impacto do pecado original em afetar nosso estado de plenitude e domínio perante o restante da Criação, que se perverteu pelo deslize cometido por Adão e Eva ${ }^{8}$ (ZATERKA, 2004). Antes do pecado original, o papel da humanidade no mundo seria destinado somente à contemplação; já com a expulsão do Éden, passaria a ter de trabalhar para a própria subsistência:

\begin{abstract}
"Terminada a criação, nos é dito que o homem foi colocado no jardim para trabalhar nele, não podendo ser outro o trabalho que se lhe assinalava que trabalho de contemplação, isto é, aquele orientado somente a exercício e experimento, e não a satisfazer uma necessidade; pois, não havendo então rebeldia da criatura nem suor de seu rosto, forçosamente a ocupação do homem teve que ser matéria de deleite no experimento e não matéria de esforço para a utilidade. Assim, as primeiras ações que o homem levou a cabo no Paraíso consistiram nas duas partes supremas do conhecimento: a visão das criaturas e a imposição de nomes. Quanto ao conhecimento que induziu à queda, foi, como mencionamos antes, não o natural da criatura, mas a moral do bem e do mal, partindo do suposto de que os mandamentos ou proibições de Deus não eram os originários do bem e do mal, mas que estes tinham outros princípios que o homem aspirou a conhecer, para desse modo desligar-se completamente de Deus e depender unicamente de si mesmo." (BACON, 2007, p. 65)
\end{abstract}

Com o pecado original, não só a relação da humanidade com a natureza dissimulou, mas também a capacidade da mente humana de obter algum conhecimento pleno da Criação. Originalmente, Deus "moldou a mente do homem como um espelho ou vidro capaz de refletir a imagem do universo" (Ibidem, p. 21), mas após a expulsão do Éden, a mente humana passaria a agir como um espelho distorcido, que desfigura a imagem do mundo, condenando o sucesso de toda representação epistemológica fidedigna da realidade. Desde então, os seres humanos foram destituídos de sua relação contemplativa com o mundo criado por Deus por causa que

"[...] sua soberba os inclinou a abandonar o oráculo das obras de Deus e a dissipar-se na mistura de suas próprias invenções, assim também, na inquisição da natureza abandonaram o oráculo das obras de Deus e adoraram as imagens enganosas e deformadas que o espelho desigual de suas próprias mentes" (BACON, 2007, p. 52).

Todavia, Bacon lembra que, assim como a religião, a ciência e suas técnicas são também meios pelos quais cabe ao ser humano redimir-se pela Queda, associando isso com a passagem do Gênesis em que Deus condena Adão ao trabalho ${ }^{9}$. Ciência e religião, para Francis Bacon, possuem a meta de restabelecer o elo que a humanidade perdeu com a Criação, cada uma ao seu modo: a ciência busca entender a obra de Deus (God's work), enquanto a religião apresenta a palavra de Deus (God's word). Pelas obras de Deus, Bacon entende serem as coisas criadas pelo poder de Deus, que cabem ao ser humano conhecer dentro de suas limitações, já que "a contemplação das criaturas e obras de Deus produz (tratando-se das obras e criaturas) conhecimento" (Ibidem, p. 23, parênteses nosso); e a palavra de Deus diz respeito aos planos e a vontade divinas,

\footnotetext{
${ }^{8}$ Essa interpretação é possível através da leitura de Gênesis 3:17, versículo qual Deus disse a Adão "maldita é a terra por tua causa".

${ }^{9}$ Gênesis 3:19
} 
fonte de toda a revelação divina e seus ditames morais. Desse modo, a reconciliação com a Criação divina restabeleceria, levando-se em consideração que "Bacon não propõe o poder pelo poder e sim um poder que tem como guia as verdades da religião" (ZATERKA, 2004, p. 98), possuindo a ciência o compromisso de sujeitar-se a ser um instrumento de manifestação da generosidade propagada pela moralidade contida na palavra de Deus. Pela palavra revelada nós realizamos a obra de Deus, e da mesma maneira, Bacon acreditava que pela ciência nós colocamos em prática um dever religioso. Devido a este compromisso de expiação do pecado pela ciência, que partilha de seus avanços com a humanidade, está dado o rigor normativo da ciência segundo o filósofo inglês.

Explicado como a ciência difundida por Bacon possui um rigor utilitário e um normativo, chegamos a entender o espírito cooperativo existente no modelo de ciência versada pelo autor. Embora seu entusiasmo de fundo teológico não tenha remanescido na ciência moderna, seu tratamento empírico e indutivo com os fatos manteve-se, como o filósofo oitocentista Augusto Comte elucida dizendo no seu Curso de filosofia positiva que "todos os bons espíritos repetem, desde Bacon, que somente são reais os conhecimentos que repousam sobre fatos observados" (1988, p.5), já que, na prática, o filósofo inglês não contribuiu com descobertas relevantes à ciência ${ }^{10}$. Reconhecendo haver um caráter utilitário e normativo na concepção de ciência dada por Bacon, é evidente que ela representa a seguinte pretensão: uma comunidade científica tal como a Casa de Salomão, que pela ciência expie a humanidade de sua queda através da técnica.

\section{II}

Apresentado os traços característicos da emenda baconiana de ciência, expomos que ela:

(i) É indutiva e experimental;

(ii) Ela é técnica, isto é, possui preocupações utilitárias em aplicar seus achados, e;

(iii)Ela é normativa, comprometendo-se, através da pesquisa e do engenho, propiciar algum benefício em prol da humanidade.

Diferente de um método racionalista como o de Descartes (SARGENT, 1996), que enfatiza a capacidade racional individual em sua filosofia, Francis Bacon institui um método de investigação natural baseado em uma força de trabalho cooperativa. Esse valor é ressaltado na Nova Atlântida, assim chamada em referência à civilização atlante ${ }^{11}$, mencionada primeiramente no diálogo Crítias de Platão. Embora haja intérpretes ${ }^{12}$

\footnotetext{
${ }^{10}$ Rees (1996, p. 121-122) aponta uma peculiaridade na filosofia baconiana: Embora sua filosofia verse edificar o conhecimento científico calcado em bases indutivas, os escritos de filosofia natural de Bacon possuem forte traço especulativo. O motivo para isso deve-se ao ecletismo intrínseco à sua física, que reúne traços de fontes diversas, como o atomismo clássico, as doutrinas de Paracelso, Copérnico, Telésio e outros.

${ }^{11}$ Mediante o governador, um dos personagens, o passado da ilha de Bensalém é contado (BACON, 1979, p. 248-253): Graças a sua localidade, fora um entreposto para embarcações de diversos povos, vindos de regiões como a China, o Egito, Cartago, Fenícia e a Atlântida (indicada na obra como o continente americano). Bensalém acaba por ser, devido isso, um centro cultural. Contudo, com o dilúvio próprio que dizimou Atlântida, a utópica ilha perdeu o seu mais próximo colega comercial. Com o tempo, as navegações nas outras partes do mundo viriam a decair, e com isso, Bensalém ficaria esquecida nesses lugares do mundo. Os moradores, desde então, passaram a viver isolados, e mesmo as expedições feitas por eles começaram a ser feitas mediante disfarces da própria origem.

${ }^{12}$ É apontado por Sargent (1996, p. 152) o fato de a Nova Atlântida ser recorrentemente interpretada como uma obra de cunho literário, embora haja os que a tomem sob um tripé político, social e religioso; e, por fim, quem adere uma leitura que a valorize como um concreto manifesto de seu plano edificador de uma sociedade científica levada a cabo.
} 
que a tomem apenas como uma obra literária utópica, outros a interpretam como um almejo de edificar uma comunidade científica. De qualquer modo, sua leitura se faz necessária para entender o projeto científico baconiano.

Escrito em formato de novela, a Nova Atlântida possui como cenário a fictícia ilha de Bensalém, situada no sul do Oceano Pacífico. William Rawley, responsável por publicar a obra após Bacon falecer, descreveu-a como uma fábula, certamente pelo teor utópico da obra em apresentar uma concepção de Estado ideal, seja pelos feitos da Casa de Salomão (sobre os quais discorreremos mais adiante) ou pela sua caridade e benevolência com a sua população. Sua estória desenrola-se com uma embarcação europeia partida do Peru que, durante sua navegação rumo ao Japão e a China, a embarcação europeia encontra uma ilha para pousar após a mudança no curso dos ventos e a escassez de provisões (BACON, 1979), acolhidos pela hospitalidade do governo ilhéu. Recepcionados pelo próprio governador da ilha, os marinheiros ouvem falar da mais prestigiosa instituição local: A Casa de Salomão, assim chamada em homenagem ao rei bíblico Salomão, apontado como um homem dotado de grande sabedoria por Deus (1 Reis 4:29-34). A Casa de Salomão foi fundada por um rei que viveu aproximadamente mil e novecentos anos atrás em Bensalém, chamado Salomona, responsável também pela legislação existente na ilha.

A Casa de Salomão é comprometida com o conhecimento, buscando-o em toda parte e o trazendo até a ilha, para auxiliar as pesquisas feitas pela instituição. Ainda que os moradores sejam proibidos de navegar fora de seu território, o reino de Bensalém envia de doze em doze anos dois navios que realizam expedições mundo afora, presente em cada navio uma comissão de três membros da Casa de Salomão. As expedições possuem o propósito de relatar a ciência, as artes e as invenções produzidas nos países visitados, e, com a cota farta de ouro dada pela instituição, comprar exemplares de livro e prestações de serviço por parte de terceiros conforme seja conveniente. Em suma, essas viagens servem para buscar "tão-somente a primeira criação de Deus, que foi a luz: para obter a luz do desenvolvimento de todas as partes do mundo" (Ibidem, p. 253), ou, como mais tarde é dito por um de seus integrantes: "O fim da nossa instituição é o conhecimento das causas e dos segredos dos movimentos das coisas e a ampliação dos limites do império humano para a realização de todas as coisas que forem possíveis" (Ibidem, p. 262), remetendo ao intento da ciência baconiana em descobrir a forma.

Obstinada a pesquisa de cunho científico, a Casa de Salomão possui lugares por toda a ilha que servem de centros de pesquisa e aprimoramento tecnológico. Muitos deles são mencionados durante um pronunciamento feito por um dos membros da instituição (Ibidem, p. 262-272), um padre que regressa à ilha de Bensalém após realizar uma das expedições do tipo citado acima. Sua chegada é celebrada pelos habitantes da ilha, e a instituição realiza preparativos para comemorar o seu regresso. Seu discurso saúda a Casa de Salomão, bem como os meios pelos quais ela realiza seus trabalhos, os ofícios dispostos a designar seus integrantes e as observâncias que ela se presta a cumprir.

Os lugares a serem utilizados pela Casa de Salomão são diversos. Por toda a ilha, há cavernas, torres, câmaras, fábricas, ambientes naturais e demais áreas utilizadas para o engenho de novas técnicas. Todas elas refletem a ambição baconiana, descrita por Sargent como "grande visão de como o trabalho cooperativo de muitos trabalhadores em busca do conhecimento pode gerar inúmeros benefícios para a comunidade" (1996, p. 151, tradução nossa). Muitos dos feitos da instituição que são citados podem soar fantasiosos ou futuristas (considerando a época em que o autor viveu), como o caso a menção das plantas sem semente usadas para o cultivo, feitas "tão somente pela mistura de terras e, igualmente, de criar diversas plantas novas e transformar árvores e plantas em uma espécie diferente" (Ibidem, p. 264); todavia, lendo a obra com a devida relação a ser estabelecida com sua filosofia, Bacon mostra 
como ele imaginava um Estado obstinado a promover não apenas o bem comum em sentido político e social, mas também a tornar a vida de seus governados mais próspera graças ao progresso técnico-científico, decorrente de sua mentalidade de que conhecimento teórico resulta a possibilidade da técnica.

Para fins ilustrativos, mencionaremos três passagens que descrevem alguns dos locais de trabalho e pesquisa da Casa de Salomão bem como os trabalhos por eles cumpridos:

(1) "Temos, ainda, fossas cavadas em diversos tipos de terreno, onde colocamos diversos tipos e cimento, como aqueles com os quais os chineses fazem a porcelana. Possuímos grande variedade deles, alguns mais delicados. E ainda uma extensa variedade de compostos de terra e de adubos para tornar a terra mais fértil" (Ibidem, p. 263)

(2) "Temos, ainda, casas grandes e espaçosas, onde imitamos e reproduzimos os fenômenos meteorológicos, como a neve, o granizo, a chuva e algumas chuvas artificiais de substâncias diferentes da água, trovões, relâmpagos, bem como criações de rãs, moscas e outros pequenos animais" (Ibidem, p. 264)

(3) “Temos também casas de perspectiva, nas quais fazemos demonstrações de todas as luzes e radiações, e cores. [...] Podemos também provocar todas as multiplicações da luz, que levamos a grandes distâncias, bem como torná-la viva a ponto de poderem ser discernidos até os menores pontos e as linhas; obtemos também qualquer colocação de luz, toda espécie de enganos e ilusões ópticas, em formas, grandezas, movimentos e cores, bem como quaisquer jogos de sombras. Descobrimos métodos, até agora desconhecidos por vós, para a produção de luz a partir de certos corpos. [...] Sabemos fabricar artificialmente o arco-íris, auréolas e círculos luminosos. Reproduzimos também todas as modalidades de reflexão, refração e multiplicação dos raios visíveis dos objetos." (Ibidem, p. 267-268).

Posteriormente, o discurso do "irmão" (como os membros chamam-se uns aos outros) da Casa de Salomão versa sobre os ofícios por ela oferecidos aos seus integrantes. Estes, por sua vez, são encarregados de buscar o conhecimento, analisá-lo e realizar testes com as hipóteses então disponíveis, como também em aplicá-las. Cada um dos cargos oferecidos pela instituição age individualmente, mas reunidos atendem aos mesmos propósitos humanitários, consoantes ao ideário baconiano, que é de "um caráter público, democrático e colaborativo, na qual esforços individuais contribuem para seu sucesso em geral" (ROSSI, 1996, p. 32, tradução nossa).

A colaboração existe como o produto de serviços individuais que atendam interesses em comum, na qual as tarefas são divididas entre os seus integrantes visando o mesmo interesse. Essa percepção de trabalho em equipe encontra-se nas entrelinhas da divisão de tarefas na Casa de Salomão, que distribui ofícios entre seus "irmãos", pelos quais cada um realiza suas tarefas que contribuam aos interesses científicos e práticos da instituição. Ao todo, são nove os ofícios oferecidos por ela em seus trabalhos científicos, todos eles refletindo não só o caráter colaborativo da ciência indutiva baconiana, como também o vínculo indissociável entre teoria e prática versado pelo filósofo londrino.

São os ofícios, respectivamente apresentados no Quadro 1, segundo a ordem com que expostos na obra.

A esse respeito, também podemos considerar as palavras de Sargent, explicando que a divisão do trabalho na Casa de Salomão provém de uma "noção de pesquisa cooperativa baseada em uma divisão racional do trabalho pode resultar em uma grande sociedade dedicada a melhorar a vida de seus membros" (SARGENT, 1996, p. 163, tradução nossa). Esses cargos oferecidos pela Casa de Salomão são cruciais para entender como Bacon idealizava uma comunidade científica. Eles são a concretização 
Quadro 1. Ofícios oferecidos pela Casa de Salomão.

\begin{tabular}{|c|c|}
\hline Ofício & Função \\
\hline Mercadores da luz & $\begin{array}{l}\text { Consistem em doze pessoas que, encarregadas de viajar em } \\
\text { países estrangeiros, recolhem exemplares de livros, invenções e } \\
\text { descobertas lá realizados. }\end{array}$ \\
\hline Depredadores & $\begin{array}{l}\text { Consistem em três pessoas encarregadas de recolher as } \\
\text { informações contidas nos livros trazidos. }\end{array}$ \\
\hline Homens do mistério & $\begin{array}{l}\text { Consistem em três pessoas que reúnem os conhecimentos } \\
\text { científicos e descobertas que não possuem, ao menos } \\
\text { inicialmente, aplicação tecnológica. }\end{array}$ \\
\hline Pioneiros ou mineiros & $\begin{array}{l}\text { Consistem em três pessoas que, instruídas dos conhecimentos } \\
\text { até então obtidos e experimentados, realizam outros que } \\
\text { considerem úteis. }\end{array}$ \\
\hline Compiladores & $\begin{array}{l}\text { Consistem em três pessoas que avaliam os trabalhos dos quatro } \\
\text { cargos anteriormente citados e organizá-los e extrair axiomas } \\
\text { delas. }\end{array}$ \\
\hline Doadores ou benfeitores & $\begin{array}{l}\text { Consistem em três pessoas que, com base naquilo feito pelos } \\
\text { grupos anteriores, procura extrair de suas contribuições alguma } \\
\text { utilidade para a vida humana. }\end{array}$ \\
\hline Luminares & $\begin{array}{l}\text { Consistem em três pessoas que orientam novos experimentos } \\
\text { com base nos já feitos. }\end{array}$ \\
\hline Inoculadores & $\begin{array}{l}\text { Consistem em três pessoas que realizam os experimentos } \\
\text { encaminhados pelos luminares. }\end{array}$ \\
\hline Intérpretes da natureza & $\begin{array}{l}\text { Consistem em três pessoas ocupadas em sintetizar as } \\
\text { descobertas anteriores, e com uma observação geral de como } \\
\text { foram concluídas, extrair axiomas de maior generalidade. }\end{array}$ \\
\hline
\end{tabular}

de seu método. A Casa de Salomão, apesar de haver cargos hierárquicos - como aprendizes e mestres - e demais empregados e serventes, são os ofícios anteriormente citados, porém, que nos interessam para entender o espírito coletivo do projeto científico de Bacon.

Por fim, o padre da Casa de Salomão menciona os ritos e serviços prestados ao reino da ilha de Bensalém. Inicialmente, menciona a presença de duas galerias que celebram grandes invenções e seus inventores. Na primeira delas, são postos modelos de invenções saudosas e raras, dignas de ali estarem. A segunda galeria abriga, por sua vez, estátuas dos principais inventores e descobridores, como a de Cristóvão Colombo por descobrir as Américas, e outros como a dos inventores da pólvora, do papel e da seda. Mais importante, no entanto, é o serviço que a Casa de Salomão presta aos moradores da ilha. Bacon descreve que ela realiza visitas periódicas nas cidades que integram o reino para fins diversos: divulgar os novos feitos da instituição, predições de prevenção às pragas, desastres naturais e preparação para estações do ano. Dentre todas as coisas, o fim de todo o labor técnico-científico da Casa de Salomão é melhorar a vida dos moradores de Bensalém, tal como o filósofo atribui à ciência o compromisso último de melhorar a qualidade da vida humana.

\section{Considerações}

Levando em conta tudo o que foi apresentado neste artigo, vimos que o filósofo inglês Francis Bacon previa, em seu método, o trabalho coletivo na investigação da natureza, seja na busca de suas leis (o que inclui não só a pesquisa, mas também, a revisão de todo o resultado dela) ou então na aplicação dessas descobertas de modo que, uma vez conhecendo a natureza, pode o ser humano operar sobre ela para proveito próprio. O império humano sobre a natureza não proveria de um uso 
instrumentalista da ciência, mas sim de uma aplicação consciente com o compromisso ético-religioso de melhorar a qualidade da vida humana e resgatar a ligação com a natureza mediante a atividade redentora da ciência.

Tal comprometimento prático delegado à ciência por Bacon reflete sua obra: seja expondo teoricamente o seu método, expondo-o no Advancement of Learning e na sua Grande Instauração (principalmente no Novum Organum), assim como também o fez literariamente na Nova Atlântida. Do mesmo modo que as obras congêneres da época, a utópica Bensalém mostra o projeto de sociedade perfeita na qual a fraternidade seja um imperativo instaurado, o que podemos perceber seja na hospitalidade da Casa de Salomão com os forasteiros ou pela empatia pela população da ilha, por quem os seus empreendimentos científicos atendem. Mesmo que inacabada, Bacon conseguiu exprimir essas intenções nas poucas páginas escritas da Nova Atlântida.

A Casa de Salomão seria o veículo pelo qual Bacon idealizava o cumprimento de um dever científico-religioso inerente ao seu sistema filosófico, sujeitando a política à ciência assim como a ciência encontra-se ao dispor da religião. Embora sem os objetivos previstos na filosofia baconiana, a comunidade científica como hoje a conhecemos segue, ao seu modo, a sua preocupação em aplicar seus conhecimentos visando a melhoria do bem-estar humano, seja com fármacos que combatam doenças, com técnicas de construção que criem edifícios mais confortáveis e seguros, ou até com aparelhos que sirvam para o lazer no cotidiano.

Correspondência: Kailani Amim Postilhoni Ferreira. Universidade Estadual Paulista - UNESP, Campus de Marília, Av. Hygino Muzzi Filho, 737, Mirante, CEP 17525 000, Marília, SP, Brasil. E-mail: kai_ferreira@yahoo.com Conflito de interesses: Nenhum.

Todos os autores leram e aprovam a versão final submetida a revista Em curso. 


\section{Referências}

BACON, F. Novum Organum; Nova Atlântida. Tradução e notas de José Aluysio Reis de Andrade. São Paulo: Abril Cultural, 1979. (Coleção Os Pensadores)

O progresso do conhecimento. Tradução e introdução de Raul Fiker. São Paulo: Unesp, 2007.

BÍBLIA SAGRADA. Tradução de João Ferreira de Almeida. Rio de Janeiro: Harpa Cristã, 2008.

COMTE, A. Curso de filosofia positiva. São Paulo: Abril Cultural, 1988. (Coleção Os Pensadores)

KENNY, A. A New History of Western Philosophy. Volume 3: The Rise of Modern Philosophy. Oxford: Oxford University Press, 2008.

MALHERBE, M. Bacon's method of science. In: PELTONEN, M (ed). The Cambridge Companion to Bacon. Cambridge: Cambridge University Press, 1996.

OLIVA, L. Algumas considerações sobre o conceito de Forma em Bacon. Cadernos de História e Filosofia da Ciência, Campinas, série. 3, v. 13, n. 1, p 33-44, jan. /jun. 2003.

REES, G. Bacon's speculative philosophy. In: PELTONEN, M (ed). The Cambridge Companion to Bacon. Cambridge: Cambridge University Press, 1996.

ROSSI, P. Bacon's idea of science. In: PELTONEN, M (ed). The Cambridge Companion to Bacon. Cambridge: Cambridge University Press, 1996.

SARGENT, R. M. Bacon as an advocate for cooperative scientific research. In: PELTONEN, M (ed). The Cambridge Companion to Bacon. Cambridge: Cambridge University Press, 1996.

STEIRIS, G. The Study of the Soul in Renaissance Utopian Literature. Agrafa: Journal of philosophy of psychoanalysis, Novi Sad, v.2, p. 57-67, 2013.

ZATERKA, L. A filosofia experimental na Inglaterra do século XVII: Francis Bacon e Robert Boyle. São Paulo: Associação Editorial Humanitas, 2004. 